\title{
Mapeamento de unidades geomorfológicas: bacias hidrográficas Arroio São João e Sanga da Divisa, Alegrete - RS
}

\author{
Cristina Braz Cardoso \\ Luis Eduardo de Souza Robaina \\ EDGARDO RAMOS MEDEIROS
}

\section{Resumo}

Este trabalho apresenta uma contribuição ao estudo das bacias dos arroios São João e Divisa, município de Alegrete (RS), onde ocorrem processos de erosão acelerada. O mapeamento permitiu separar em cinco unidades geomorfológicas usando atributos como morfometria, geologia, solos, processos erosivos, uso da terra e vegetação. O mapeamento é uma ferramenta indispensável para o planejamento e gerenciamento de áreas com erosão acelerada. 


\section{Abstract}

This paper presents a contribution for study from the São João and Divisa Basin, Alegrete county (RS), where occur growing erosion. With of the mapping was possible separate five individual geomorphologic units using attributes included morphometric, geological, soil, erosion process, land use and vegetation. The mapping is an indispensable tool to aid and to manage in areas with growing erosion.

Key Words: Alegrete, mapping, environment management

\section{Introdução}

A degradação dos solos é considerada um dos mais importantes problemas ambientais dos nossos dias. São conhecidas, nas diversas regiões brasileiras, áreas que apresentam processos avançados de degradação provocados por práticas inadequadas de manejo de solos.

Numa escala regional, o tema reveste-se de importância na medida em que o estudo das áreas degradadas, do Sudoeste do Rio Grande do Sul pode contribuir para o entendimento de uma das mais significativas preocupações ecológicas no Estado, que são os núcleos de arenização (erroneamente chamados de "desertos").

Neste contexto, foram escolhidas como áreas de estudo duas bacias hidrográficas localizadas no município de Alegrete - RS. Estas bacias denominam-se Arroio São João e Sanga da Divisa, que compõem parte da margem esquerda do Rio Ibicuí.

Estas bacias estão delimitadas pelas coordenadas geográficas: $29^{\circ} 35^{\prime} 41^{\prime \prime}$ e $29^{\circ} 50^{\prime} 10^{\prime \prime}$ de latitude sul e $55^{\circ} 12^{\prime} 56^{\prime \prime}$ e $55^{\circ} 31^{\prime} 47^{\prime \prime}$ de longitude oeste (FIGURA 01). De acordo com o IBGE (1997), inserem-se na mesorregião Sudoeste do Rio Grande do Sul, a qual apresenta expressiva ocorrência de áreas arenosas, desprovidas de vegetação.

Neste trabalho, busca-se através de uma visão integradora a distribuição espacial dos elementos do meio ambiente, enfatizando as peculiaridades que são fundamentais para alcançar o entendimento dos processos dinâmicos que ocorrem no sistema com a ativa participação antrópica. 


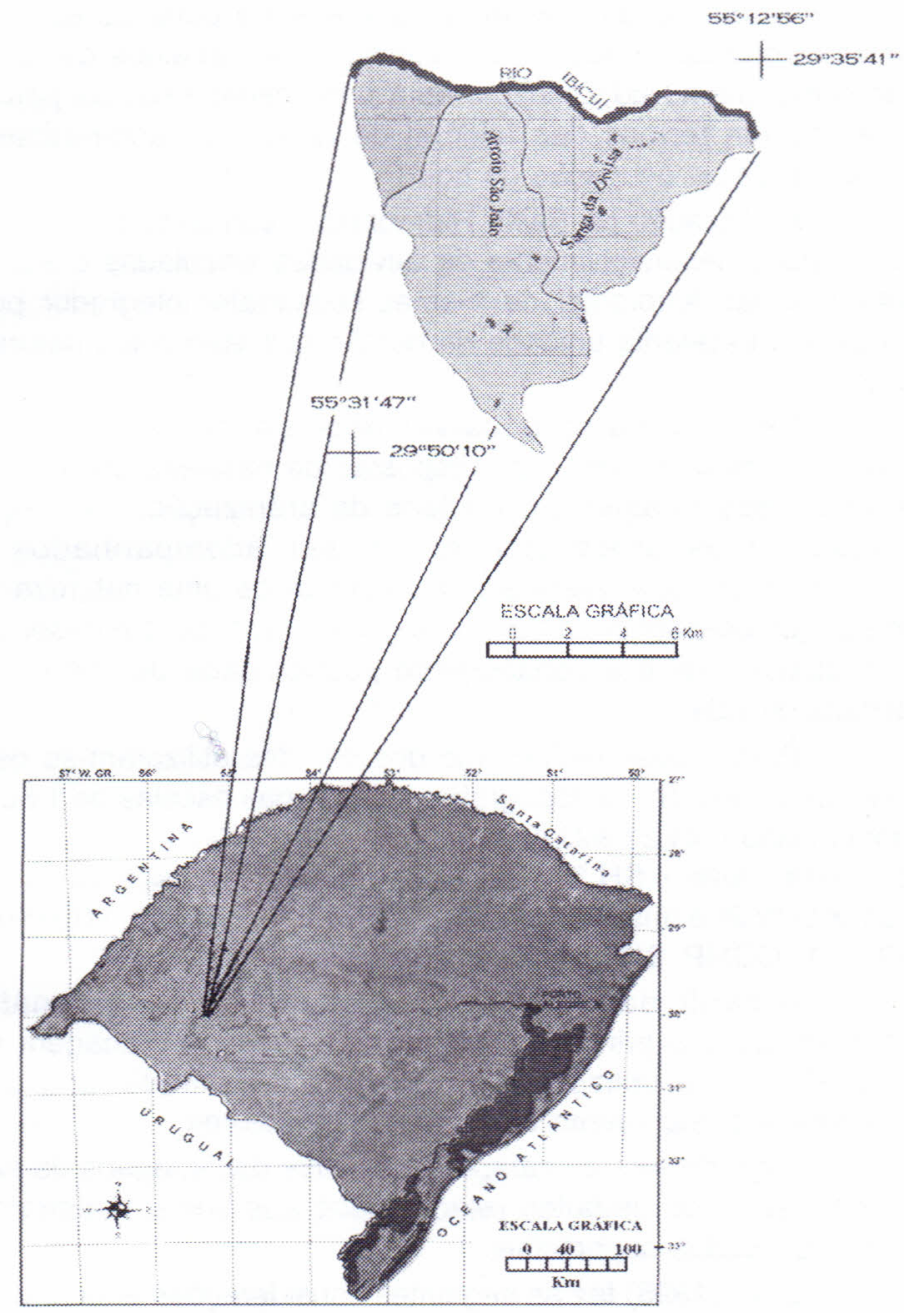

Fig. 1. Mapa de localização das Bacias Hidrográficas Arroio São João, Sanga da Divisa e Arroio Sem Nome no Estado do Rio Grande do Sul

FONTE: Adaptado de Suertegaray, D. M. et al (2001) 


\section{Metodologia}

Conforme Lollo (1996), a sistemática de avaliação de terrenos baseia-se na possibilidade de divisão da área estudada em unidades de terreno. Essa divisão se estabelece a partir do estudo de cartas topográficas, imagens de satélite e de trabalhos de campo, tendo como critério de zoneamento a uniformidade destas parcelas de terreno em termos das feições de relevo, características do substrato e uso e ocupação do solo.

A utilização de Bacia Hidrográfica, como unidade de referência para o desenvolvimento de atividades vinculadas a Planejamento e Gestão Ambiental, deve-se ao seu caráter integrador, pois é considerada excelente unidade de gestão dos elementos naturais e sociais.

Nesta ótica, é possível acompanhar as mudanças introduzidas pelo homem e as respostas da natureza como erosão dos solos, desmatamentos, núcleos de arenização, inundações, poluição, cujos processos devem ser acompanhados por monitoramentos, que levem à compreensão de uma natureza integrada e, que possam contribuir, de alguma forma, para o desenvolvimento sustentável e a conseqüente possibilidade de melhoria da qualidade de vida.

Para o desenvolvimento dos estudos utilizaram-se os seguintes materiais: cartas topográficas, DSG, nas escalas de 1:50.000 (Manoel Viana - SH.21.X.D.IV.1, Passo Novo - SH.21.X.C.VI.2, Rincão dos Costa Leite - SH.21.X.D.IV.3 e São Francisco de Assis SH.21.X.D.IV.2) e imagem de satélite (TM-LANDSAT 5, 11/01/97, O/ P 224_81, COMP. 3/4/5, escala 1:50.000).

A partir das cartas topográficas fez-se as análises morfométricas dos principais atributos da rede de drenagem e do relevo. Para isso utilizou-se parâmetros de altitude, amplitude, declividade e comprimento de rampa das vertentes.

Os trabalhos de campo e a análise das imagens de satélite identificaram os atributos relacionados aos solos, substrato rochoso e depósitos superficiais.

Lollo (1996) faz as seguintes considerações acerca da sistemática:

- A técnica de avaliação do terreno baseia-se na possibilidade de divisão da área estudada em unidades cada vez menores (em função da escala e da finalidade pretendida) a partir do uso de fotografias aéreas (preferivelmente), imagens de satélite e de trabaIhos de campo, tendo-se como critério de zoneamento a uniformida- 
de destas parcelas do terreno em termos das feições de relevo encontradas;

Do ponto de vista da maneira de se avaliar o terreno utilizou-se duas modalidades de análise, denominadas enfoque fisiográfico ou da paisagem e enfoque paramétrico;

- O enfoque fisiográfico ou da paisagem consiste na delimitação de diferentes feições de relevo, com base num conjunto de observações fotointerpretativas e de campo, promovendo o zoneamento da região estudada em termos de áreas consideradas semelhantes ou que apresentem um grau de heterogeneidade mínimo;

- O enfoque paramétrico tem o mesmo objetivo (delimitação de áreas diferentes do ponto de vista fisiográfico), porém a análise é feita com base na medida de parâmetros representativos da geometria das vertentes como declividade, amplitude, extensão e parâmetros característicos da rede de drenagem;

Obtido este zoneamento (seja através do enfoque paramétrico ou do enfoque da paisagem) pode-se, então, cartografar as unidades.

A obtenção das informações seguiu os princípios básicos de coleta e análise de atributos, que foram fundamentais para a definição das unidades, conforme as diferentes especificidades do mapeamento. A partir desses dados, elaborou-se um mapa com unidades homogêneas. (FIGURA 02)

\section{Discussão dos dados}

Os estudos geomorfológicos são muito importantes para o entendimento da relação existente entre as formas e os processos que constituem um sistema geomorfológico. A análise das formas e processos fornece conhecimento sobre os aspectos e a dinâmica da topografia atual, possibilitando compreender as formas esculpidas pelas forças erosivas e as originadas nos ambientes deposicionais. Assim, o estudo dos processos atuais e das características dos ambientes de sedimentação propicia a orientação e interpretação dos depósitos antigos. Nesse sentido as mudanças nas condições ambientais possibilitam decifrar a evolução da topografia regional e melhor compreender as características da atual morfologia da paisagem.

Casseti (1994) diz que "os fatores endógenos como os exógenos são 'forças vivas' que, ao longo do tempo geológico, sofre- 
ram grandes transformações, o que leva a entender que o relevo terrestre não foi sempre o mesmo e está em constante evolução". Este autor defende que o relevo assume importância fundamental no processo de ocupação dos espaços. Assim, observa que o estudo geomorfológico de uma área é fundamental para conhecer o potencial de suporte ou recurso, cujas formas ou modalidades de apropriação respondem pelo comportamento da paisagem.

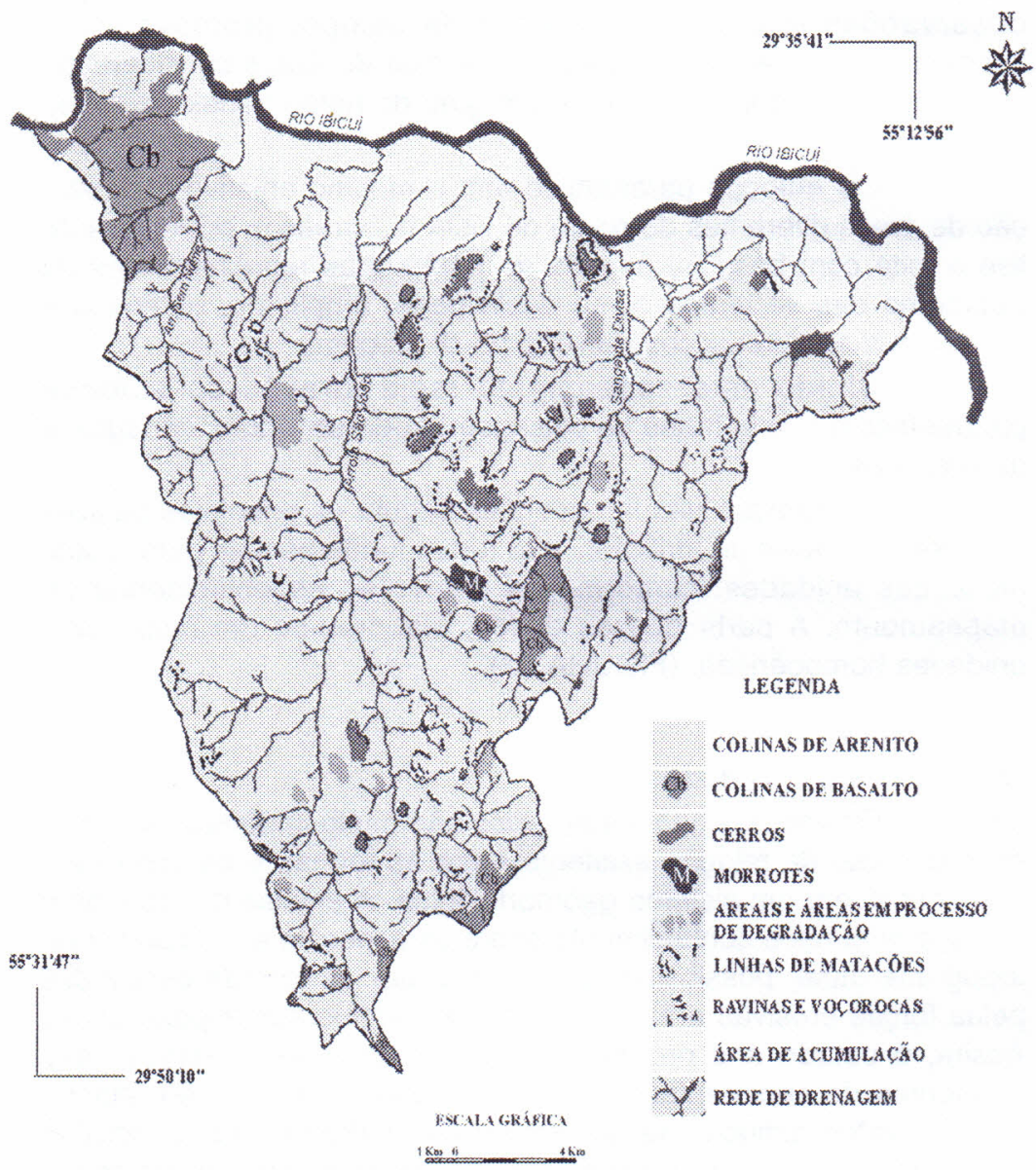

Base Cartográfica: Cartas da DSG Org: CARDOSO, Cristina Braz

Fig. 2. Mapa das unidades geomorfológicas e os impactos ambientais nas bacias hidrográficas Arroio São João e Sanga da Divisa 
Para Ab'Saber apud Casseti (1994), três níveis de tratamento devem ser adotados apara a análise dos problemas geomorfológicos e ambientais, que são: 1) reconhecimento da compartimentação topográfica; 2) análise da estrutura superficial e 3) análise da fisiologia da paisagem, pela observação dos processos morfoclimáticos atuantes, aliados à ação do homem.

A partir da década de 80, conforme Guerra \& Cunha (1999), a Geomorfologia tem se caracterizado por enfatizar os problemas ambientais, possuindo um caráter integrador, na medida que proporciona compreender a evolução espaço-temporal dos processos do modelado terrestre, tendo em vista escalas de atuação desses processos, antes e depois da participação humana, em um determinado ambiente. Assim, a compreensão dos processos de evolução do relevo e dos impactos causados pela ação antrópica, tem dado uma contribuição relevante no diagnóstico da degradação ambiental, bem como tem apontado soluções para resolver esses problemas.

A técnica de avaliação de terrenos vem sendo mundialmente utilizada com grande êxito, sendo o critério preliminar de zoneamento do meio físico. Esta técnica tem como princípio a elaboração dos mapas a partir da delimitação das unidades morfológicas de forma hierárquica, considerando a evolução de uma área em termos do perfil de alteração, geologia, hidrologia, dentre outros.

\section{Unidades geomorfológicas}

A análise consistiu na delimitação de diferentes feições e relevo, geológicas e de depósitos superficiais, com base no conjunto de observações fotointerpretativas e de campo, permitindo o zoneamento da região estudada em termos de áreas consideradas semelhantes ou que apresentaram um grau de heterogeneidade mínimo.

\subsection{Unidades de colinas}

Esta unidade é definida pela análise do relevo, se caracterizando por vertentes com declividades menores que $15 \%$ e amplitudes inferiores a $100 \mathrm{~m}$.

São divididas conforme as características do substrato rochoso, que se diferenciam na resposta dos processos superficiais. 


\subsubsection{Colinas de Arenito}

Representam a unidade mais significativa da área de estudo. $O$ relevo é definido por altitudes que variam de $140 \mathrm{~m}-180 \mathrm{~m}$; as vertentes apresentam amplitudes médias de $60 \mathrm{~m}$ e declividade entre $4 \%$ e $8 \%$.

O substrato rochoso é composto por arenitos eólicos e fluviais, com baixa coesão, predominantemente silicosos, cimento de óxido de ferro cobrindo os grãos e baixa percentagem de matriz.

Os solos se caracterizam por baixo conteúdo orgânico; formam predominantemente, latossolos e, menos comumente, argissolos; quando o conteúdo de argila é inferior a 15\% representam os neossolos quartzênicos que ocorrem associados.

Os processos geomorfológicos atuantes estão relacionados à erosão que ocorre durante os períodos de chuvas intensas, desenvolvendo-se na forma laminar e em sulcos, formando ravinas (FIGURA 03).

A cobertura vegetal de gramíneas é esparsa com baixa proteção à ação erosiva.

O uso do solo é o pastoreio extensivo e a plantação de soja.

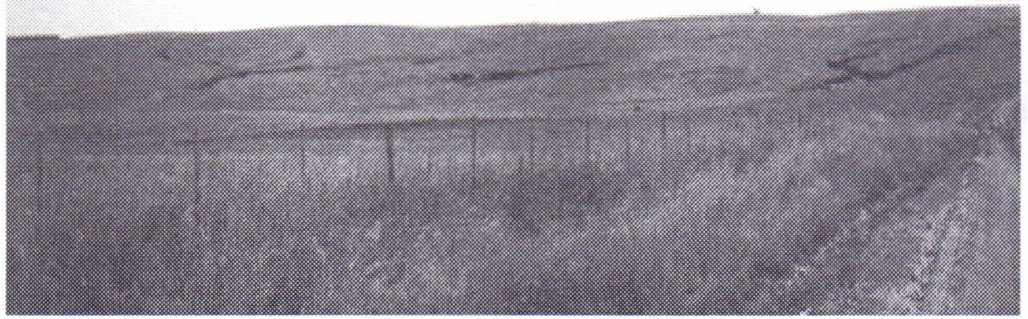

Fig. 3. Colina de arenito com processos erosivos atuantes 


\subsubsection{Colinas de Basalto}

Quanto ao relevo, são colinas que ocorrem entre as altitudes de $140 \mathrm{~m}$ a $200 \mathrm{~m}$; as vertentes apresentam amplitudes, em geral, pouco superiores às colinas de arenitos, com média de $70 \mathrm{~m}$. A declividade das vertentes está entre $4 \%$ e $8 \%$.

O substrato rochoso é composto por derrames vulcânicos pouco espessos, de composição básica. $\mathrm{Na}$ área, são identificados dois derrames com arenito intertrápico.

Os solos são do tipo Latossolo Vermelho Escuro textura argilosa, formada a partir da alteração do basalto da Formação Serra Geral, Argissolos Vermelho Escuro e Cambissolos (EMBRAPA, 1999).

A vegetação característica está representada por gramíneas com cobertura de solo superior às das colinas de arenitos.

Os processos geomorfológicos de transporte de massa são menos expressivos neste compartimento devido a maior coesão dos solos. O uso também está associado ao pastoreio e plantação de soja.

\subsection{Unidades de Declividades superior a $15 \%$}

\subsubsection{Cerros de Arenito}

Os cerros mesetiformes são mantidos por camadas coesas de arenito fluvial, fortemente silicificado, que se superpõem as outras camadas friáveis do mesmo arenito. Tal alternância de coesão diferenciada entre as camadas explica a queda de blocos do arenito por gravidade, que dão as vertentes, do topo à base, um aspecto de topografia ruiniforme.

Os cerros são feições importantes e ocupam área expressiva na região. São as áreas com maiores altitudes, sendo comum cotas superiores a $200 \mathrm{~m}$. São constituídos predominantemente por arenitos fluviais com grânulos esparsos de sílica e menos comumente por "bolas" de argila. Exemplos bem característicos são os Cerros do Tigre e Negro, localizados na bacia do Arroio São João.

Uma feição ruiniforme do Cerro do Negro é a "Ponte da Natureza" (FIGURA 04), que foi formada pela resistência diferencial a alteração e erosão entre arenitos com cimentação silicosa e os com cimento de óxido de ferro. 


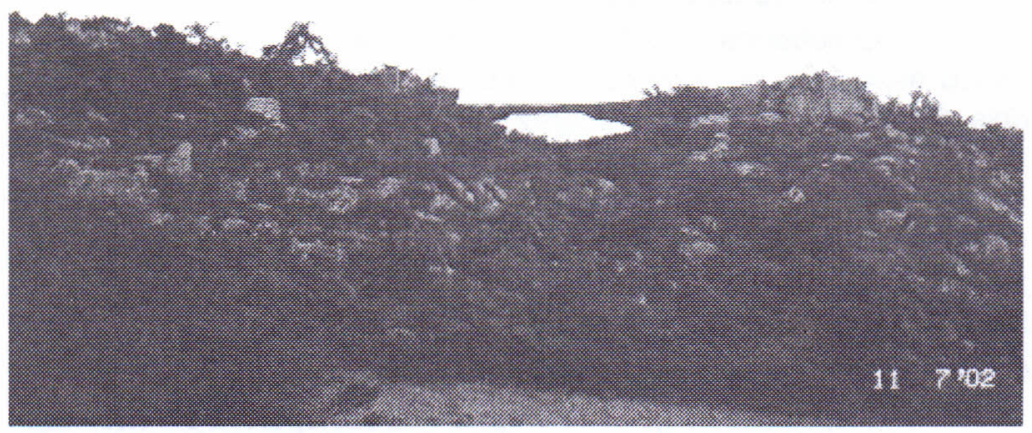

Fig. 4. "Ponte da Natureza", feição ruiniforme do Cerro Negro

Ocorrem na parte superior de amplas colinas, constituindo feições com amplitude pouco superior a $20 \mathrm{~m}$. As vertentes apresentam elevadas declividades, formando escarpas com o topo reto (FIGURA 05).

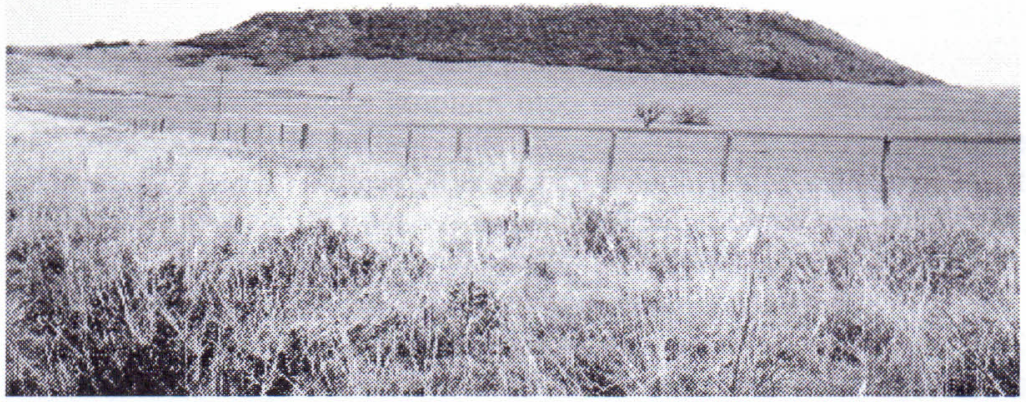

Fig. 5. Cerro de Arenito 
A vegetação arbustiva ocorre associado a zona de fratura do arenito. No topo ocorre uma área pedregosa com solo muito raso ou inexistente. Chama a atenção o número significativo de palmeiras na meia-encosta.

\subsubsection{Morrotes}

Esta unidade está representada por elevações com topos arredondados e vertentes cobertas por vegetação, formados por basalto (FIGURA 06). Ocorrem afloramentos de rocha na forma de lajeados e blocos.

As amplitudes são pouco superiores a $20 \mathrm{~m}$ e a encosta é íngreme. $\mathrm{Na}$ base da vertente, os depósitos de colúvio proporcionam a ocorrência de uma vegetação de médio a grande porte distinta das demais da área.

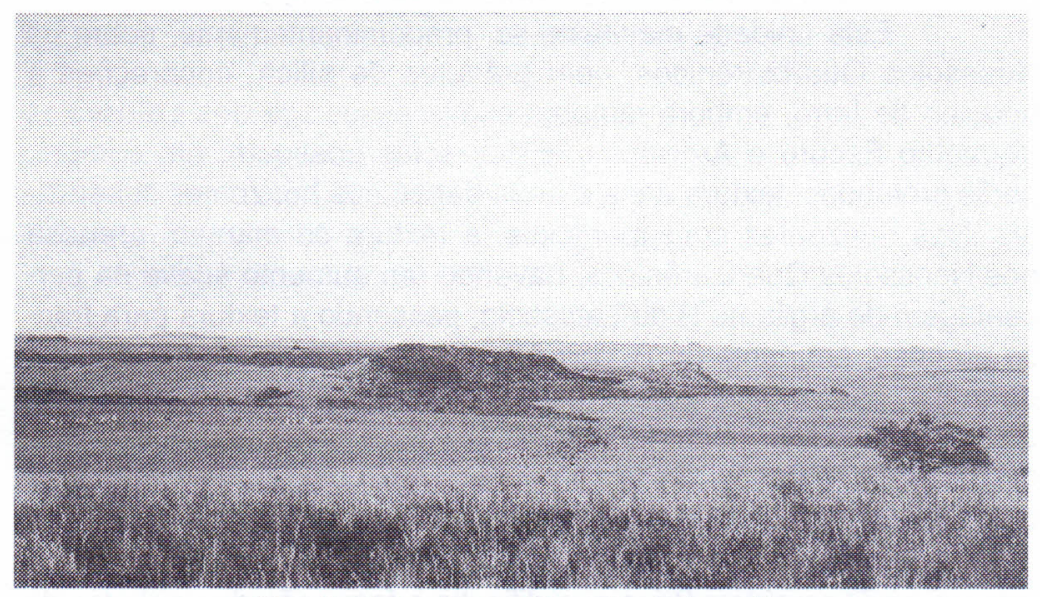

Fig. 6. Vista de um Morrote de basalto 


\subsection{Unidades de Erosão Acelerada}

\subsubsection{Areais e Áreas com Processos de Arenização}

Areais e áreas com processos de arenização formam importantes feições na paisagem devido ao grau de degradação ambiental que representam e da dificuldade de utilização destas unidades pelo proprietário da terra.

Os grandes areais se desenvolvem associados a base dos cerros, inicialmente pela ação das chuvas, em um solo de baixa cobertura vegetal, friável e arenoso. Posteriormente, o vento, persistente na região, espalha a areia, formando os campos de areia, ou seja, o retrabalhamento de depósitos areníticos pouco ou nada consolidados, promove a mobilidade dos sedimentos não protegidos pela vegetação. Esse processo de desagregação é contínuo e intermitente e por esta razão é que se verifica a grande expansão desses núcleos na região, levando a conclusão de que a arenização não ocorre somente por deficiência hídrica, mas também por excesso de chuva.

A ocorrência destes campos tem registros antigos e está relacionada à erosão geológica, porém, a ação antrópica de ocupação e o aumento da exploração destes sistemas, aceleram as taxas de ocorrência do processo degradativo (FIGURA 07).

Esta unidade manifesta-se, predominantemente, sobre os Neossolos Quartzarênicos, com grânulos de sílica, concreções e nódulos de ferro, embora também esteja associada aos Latossolos Vermelho Escuro e Argissolos. Estes solos possuem, em comum, perfis profundos, textura areia e areia franca nos horizontes superficiais. Nos horizontes subsuperficiais, a textura se mantém arenosa nos Neossolos Quartzarênicos, havendo um aumento suave na percentagem de argila no $B$ do Latossolo, passando a textura para franco arenosa, enquanto no $\mathrm{B}$, dos Argissolos há um aumento abrupto da argila, passando a textura para franca argilo arenosa. Este horizonte possui forte limitação natural quanto a fertilidade e alta susceptibilidade à erosão, devido a pobreza do substrato no material do qual se originaram e em razão de sua granulometria grosseira.

Os solos originados destas formações arenosas apresentam um perfil granulométrico que dificulta a formação de unidades de estrutura - baixos teores de argila e matéria orgânica (M.O.). Isto Ihes confere um caráter extremamente débil de resistência aos processos erosivos, quer de origem hídrica ou eólica. Por outro lado, os baixos teores de argila e M.O. imprimem ao solo propriedades físicoquímicas que se refletem na retenção dos nutrientes essenciais ou 
das substâncias portadoras destes nutrientes em níveis muito baixos ou insuficiente. Também, o armazenamento de água torna-se difícil, provocando consideráveis déficits hídricos, mesmo em curtos períodos de estiagem. Aliando a ocorrência de ventos e a má distribuição das chuvas, apesar de elevada precipitação média anual (1.400 $\mathrm{mm}$ ), cria-se as condições para o aparecimento de processos erosivos.

A arenização no sudoeste do RS deve ser entendida como o final de um processo de degradação ambiental. Ela é, entre outros, o resultado da devastação das matas ciliares, da eliminação da cobertura vegetal e do uso indevido do solo, que provocam erosão acarretando o transporte de considerável volume de terra aos arroios e rios, assoreando-os de modo significativo, alternando o ecossistema do local e finalizando por mudar a paisagem da região.

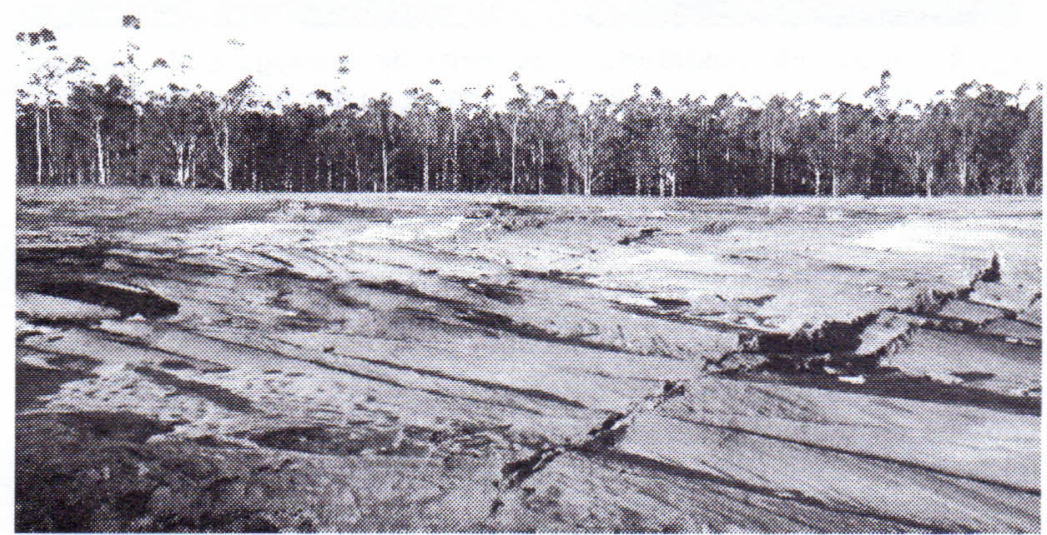

Fig. 7. Vista parcial do Areal São João, com plantação de eucalipto para conter o avanço do areal 


\subsubsection{Ravinas e Voçorocas}

As ravinas e as voçorocas são elementos importantes da paisagem e formam sulcos de profundidade ao redor de $3 \mathrm{~m}$ e largura menores que $10 \mathrm{~m}$, com poucas ramificações se desenvolvem associados às cabeceiras de drenagem e junto aos cerros (FIGURA 08), devido à intensificação do escoamento na zona de contato entre o arenito silicificado e $\mathrm{o}$ arenito friável na base.

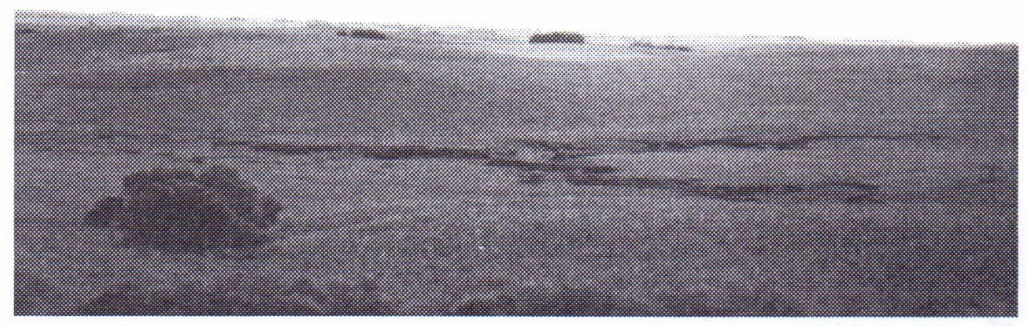

Fig. 8. Fotografia mostrando cabeceiras de drenagens de um dos afluentes do Arroio São João, com ação dos processos erosivos formando a feição de vale ravina

\subsection{Unidade de Linhas de Matacões}

O termo linha de matacão foi utilizado em substituição a campos de matacões, por considerarmos um melhor indicativo da feição observada (FIGURA 09). Estas linhas ocorrem junto a meia encosta de algumas colinas, formando um alinhamento, de blocos e matacões de arenitos silicificados com espessura média de $5 \mathrm{~m}$ e são comuns também, junto às encostas dos cerros. Quando destacados na meia encosta dão para a colina um aspecto de rampa. 


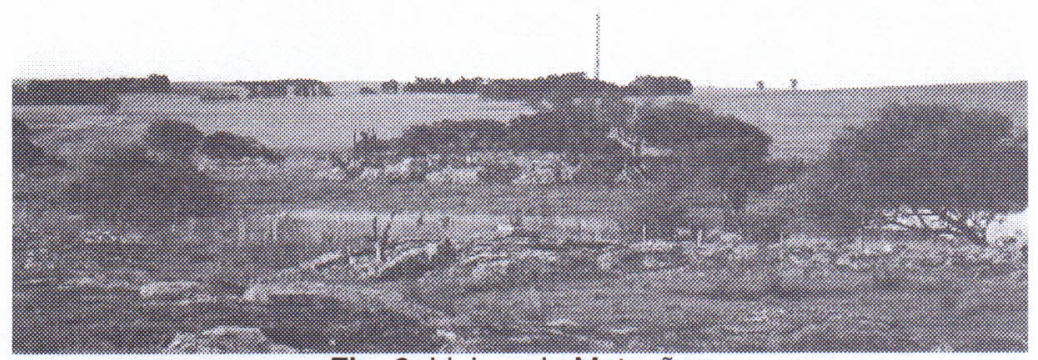

Fig. 9. Linhas de Matacões

\subsection{Unidade de Acumulação}

As unidades de acumulação representam as zonas de deposição atual da drenagem formando ampla superfície junto ao Rio Ibicuí (FIGURA 10).

Os Planossolos e Glei, encontrados em relevo plano a suave ondulado da planície de inundação do Ibicuí e das bacias de estudo, apresentam gradiente textural abrupto entre os horizontes superficiais e subsuperficiais, com profundidade média e drenagem imperfeita (EMBRAPA, 1999). Em razão da textura média superficial e argilosa subsuperficial, estes solos são adequados para irrigação por inundação e, por conseguinte, para o cultivo de arroz irrigado.

As matas ciliares estão moderadamente preservadas junto ao rio Ibicuí, porém ao longo do Arroio São João e Sanga da Divisa encontra-se uma vegetação arbórea secundária.

\section{Considerações finais e recomendações}

Os estudos propiciaram a construção de um mapa geomorfológico. Este produto cartográfico permitiu analisar os aspectos do meio físico e antrópico, definindo as áreas mais homogêneas. A partir desta informação foram estabelecidas as 
potencialidades e os prováveis problemas. Este mapa, portanto, foi um instrumento de planejamento, que permitiu indicar formas de uso e manejo mais adequado do solo.

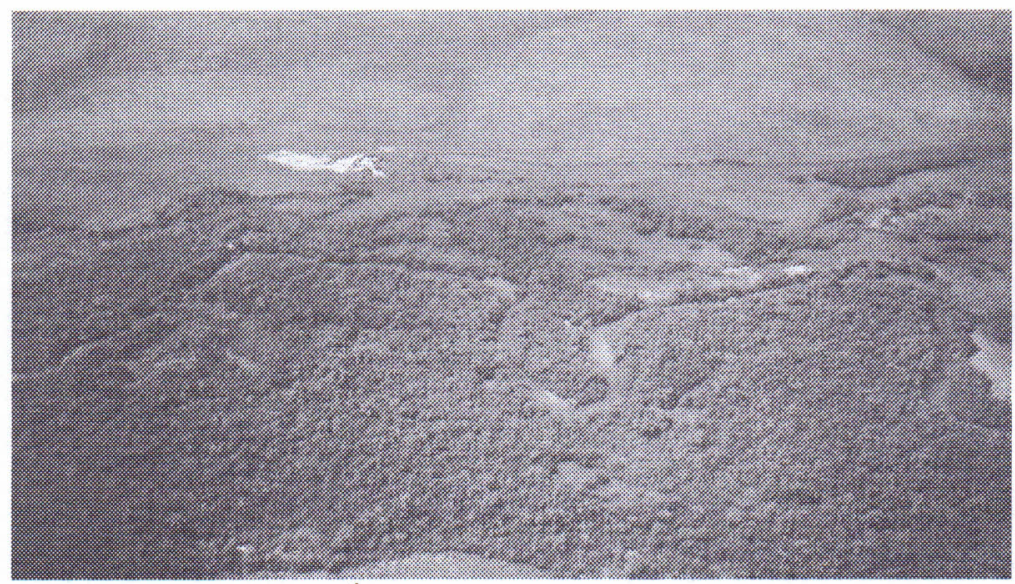

Fig. 10. Área de acumulação - Rio Ibicuí

A partir da construção do mapa geomorfológico, verificouse a distribuição dos areais nas bacias em estudo, destacando-se a bacia do Arroio São João.

Para uma maior confirmação quantificou-se (Tabela 01) a extensão destes areais por bacias, sendo possivel estabelecer uma hierarquia dos dados no sentido de comprovar qual bacia apresenta maior ocorrência.

Como se pode verificar na Tabela 01, a bacia São João apresentou maiores extensões de areais, o que permite concluir que estes areais ocorrem sobre unidade litológica susceptível ao retrabalhamento.

É evidente a fragilidade morfogenética da área e, em decorrência, a vulnerabilidade de determinada unidade litológica ao retrabalhamento (arenização), mas a ocorrência de novos areais de menor expressão e provavelmente mais recentes, está associada, ao que tudo indica, à atividade antrópica. Os areais ocorrem em alti- 
tudes e declividades variadas e estão, em alguns casos, vinculados aos processos de voçorocamento.

Tabela 1. Quantificação dos areais na área de estudo (Ago/2002).

\begin{tabular}{cccc}
\hline $\begin{array}{c}\text { Bacias } \\
\text { Hidrográficas }\end{array}$ & $\begin{array}{c}\text { Área das Bacias } \\
\text { (ha) }\end{array}$ & $\begin{array}{c}\text { Área de Areais } \\
\text { (ha) }\end{array}$ & $\begin{array}{c}\text { \% de areais na } \\
\text { área da bacia }\end{array}$ \\
\hline São João( ${ }^{*}$ ) & $28.586,20$ & 357,1502 & 1,3434 \\
Sanga da Divisa & $19.187,83$ & 93,9857 & 0,4899 \\
\hline TOTAL & & 451,1359 & \\
\hline
\end{tabular}

Os números significativos de areais da bacia São João estão localizados no sul (à montante), correspondendo as áreas bem individualizadas. Nesta bacia, o areal mais extenso, chamado "Deserto de São João", localiza-se no médio curso da drenagem, e está em processo de "recuperação".

No final dos anos 80 e início dos anos 90, ocorreram tentativas de recuperação dessas áreas. Uma das alternativas utilizadas foi o florestamento com espécies exóticas como eucaliptos e pinus, que servem como barreiras ao vento. Este ato possibilitou incorporar as áreas ao processo produtivo.

O florestamento tem sido utilizado como medida efetiva de recuperação de áreas degradas, embora, segundo Lima (1993) apud Surtegaray (1998), a interação em longo prazo de espécies florestais com solo possa conferir diferentes efeitos, quanto à dinâmica do sistema radicular, às características da serrapilheira, às atividades biológicas e a interceptação da luz.

Marchiori (1995) considera que o estabelecimento de florestas apresenta uma vantagem na proteção dos solos, minimizando a ação erosiva da chuva e vento e, além disso, os Eucaliptos não são invasores. 
A utilização dos solos aptos para cultura, como os latossolos vermelhos e argissolos, que estão associados às colinas de arenito e basalto, devem ser processados por meio de práticas de manejo adequadas, como plantio direto, construção de terraços e canais escoadouros vegetados para controlar o escoamento superficial. As colinas de arenito apresentam alto grau de risco ao desenvolvimento de processos erosivos e, com uso de sistemas agrícolas inadequados, estão sujeitas a arenização.

Os cerros apresentam características particulares quanto ao substrato rochoso, relevo e vegetação, podendo ser incorporados em propostas de educação ambiental e turismo ecológico.

Junto às linhas de matacões, os processos erosivos se acentuam, gerando ravinas e áreas de arenização. Dessa forma, nessas áreas, junto a meia encosta das colinas, é importante a recuperação de uma vegetação nativa que minimize a ação do escoamento superficial no contato rocha silicificada e friável.

Nas áreas de acumulação, os solos são adequados para a irrigação por inundação e, por conseguinte, para o cultivo de arroz irrigado.

Outra questão refere-se ao uso da água, que deve ser regulado, pois, mudanças nas condições hidrodinâmicas provocados pela retirada em excesso, pode favorecer a dinâmica erosiva. A preservação e recuperação das matas ciliares desempenham um papel fundamental na dinâmica fluvial, bem como na manutenção de espécies da fauna da região.

Especiais atenções devem ser dedicadas aos Neossolos Quartzarênicos, (solos que dão origem aos núcleos de arenização), pois podem sofrer erosão eólica pela remoção da cobertura vegetal e exposição das areias à ação de vento e à erosão hídrica, pela redução de infiltração de água em áreas compactadas devido ao trânsito de animais ou máquinas e equipamentos agrícolas. Desse modo, deve haver a redução do pisoteio de animais e, se possível, incremento da vegetação, com espécies adaptadas às condições de baixa fertilidade, baixa capacidade de retenção de água pelo solo, e que se caracterizam pela resistência dos tecidos à agressão pela areia carregada pelo vento.

Visando a atenuar os impactos ambientais, foram estabelecidas algumas medidas mitigadoras:

- Adequar a lotação de animais por hectare, evitando assim o superpastoreio causador da erradicação da cobertura vegetal e, conseqüentemente da formação de núcleos de arenização; 
- Usar práticas conservacionistas do solo e água, para evitar o impacto direto das gotas de água das chuvas sobre o solo e o escoamento superficial dessas águas. Pode-se tomar como base os estudos realizados por Nolla (1982), para evitar a erosão do solo;

- Deve-se fazer o cultivo das pastagens permanentes, que mantenham o solo coberto, para evitar a ação dos agentes erosivos;

- Construção de quebra-ventos, para reduzir a velocidade dos ventos locais. Essa medida serve para evitar que os núcleos de arenização se expandam e que ocorra a formação de novos;

- Evitar queimadas generalizadas, que causam a destruição da matéria orgânica e da microbiota do solo;

- Incentivar a fruticultura, em especial a citricultura. Pois conforme estudos realizados por Mota (1990), a região Sudoeste do estado é propícia para a produção de citrus, tanto para consumo "in natura", como para a indústria (suco);

- Utilização de plantio direto para as culturas anuais, de maneira a manter o solo sempre coberto;

- Revegetar as margens dos cursos d'água, para manter um equilíbrio dos ecossistemas;

- Nas áreas já arenizadas, deve-se fazer uso de anteparos físicos, para evitar que os núcleos de arenização aumentem de tamanho;

- Procurar isolar as áreas limítrofes aos núcleos de arenização, para evitar o pastoreio de animais e proteger a flora remanescente;

Os resultados obtidos mostram que o produto cartográfico é uma importante ferramenta para a gestão ambiental, sendo, portanto, um instrumento de planejamento.

Dessa forma acredita-se que o trabalho proposto representa uma contribuição para o conhecimento científico, o que permitirá estabelecer um planejamento para os usos e ocupação do solo na região estudada, pois a bacia hidrográfica é uma unidade espacial de planejamento que favorece a integração de práticas de uso e manejo do solo e água, criando condições compatíveis para atividade produtiva e conservação. 


\section{Referências bibliográficas}

CASSETI, V. Elementos da Geomorfologia. Editora da Universidade Federal de Goiânia. Goiânia.1994. 137 p.

EMBRAPA. Sistema brasileiro de classificação de solos. Brasília: Embrapa produção de informação; 1999. 412p.

GUERRA, A. J. T. \& CUNHA, S. B. da. Erosão e Conservação dos Solos: Conceitos, Temas e Aplicações. Rio de Janeiro: Bertrand Brasil, 1999. 339p.

LOLLO, J. A. de. O uso da técnica de avaliação do terreno no processo de elaboração do mapeamento geotécnico: sistematização e aplicação na quadrícula de Campinas. Tese de doutoramento, EESC/USP, São Carlos, 2v, 1996, 253p.

MARCHIORI, J. N. C. Vegetação e Areais no Sudoeste RioGrandense. Ciência e Ambiente. Santa Maria: Editora da Universidade. UFSM. Vol.11, p. 81-92. 1995.

MOTA, F. S. Regionalização da citricultura no sul do Rio Grande do Sul In: Lavoura Arrozeira, 43(391): 21-22, Porto Alegre, Jul/Ago, 1990.

PAULA, P. M. de Mapeamento geológico-geomorfológico na Bacia do Lageado Grande, Alegrete -RS. Santa Maria, UFSM. 2002. (Monografia).

SUERTEGARAY, D. M. A. Deserto Grande do Sul: Controvérsia. Porto Alegre: Ed. da Universidade/UFRGS, 1998. 71 p. il.

SUERTEGARAY, D. M. A.; GUASSELLI, L. A.; VERDUM, R. Atlas de Arenização : Sudoeste do Rio Grande do Sul. Porto Alegre,Secretaria da Coordenação e Planejamento, 2001. 84p. il.

Cristina Braz Cardoso cardoso_crisbraz@yahoo.com.br Geógrafa - Pós-graduanda em Geociências

Edgardo Ramos Medeiros

Prof. Msc. do Departamento de Geociências - CCNE

Luis Eduardo de Souza Robaina lesro@hanoi.base.ufsm.br

Prof. Dr. do Departamento de Geociências - CCNE LAGEOLAM - Lab. de Geologia Ambiental UFSM - Santa Maria, RS - Brasil 